Thorax (1958), 13, 267.

\title{
THE RELATION OF MEDIAL THICKNESS OF SMALL MUSCULAR PULMONARY ARTERIES TO IMMEDIATE POSTNATAL SURVIVAL IN PATIENTS WITH VENTRI- CULAR SEPTAL DEFECT OR PATENT DUCTUS ARTERIOSUS
}

\author{
BY \\ DONALD HEATH, ${ }^{*}$ H. J. C. SWAN, JAMES W. DuSHANE, AND JESSE E. EDWARDS \\ Fiom the Sections of Paediatrics, Physiology, and Pathologic Anatomy, Mayo Clinic and Mayo Foundation, \\ Rochester, Minnesota
}

(RECEIVED FOR PUBLICATION APRIL 8, 1958)

The observation at necropsy of a patent ductus arteriosus in patients dying in the neonatal period is virtually universal. As a rule this observation is of no practical significance since death is caused by one of a large group of conditions not necessarily related to the cardiovascular system. Occasionally the finding is of importance, as in two male infants, with widely patent ducti, whom we studied recently. Both had died on the second day of life from pulmonary oedema. The onset of oedema in both patients appears to have been related to the state of the muscular pulmonary arteries, which had undergone an unusually rapid transition from the foetal to the adult form so that they appeared much thinner than comparable vessels seen in the normal infant of this age or in one with a defect allowing communication between the systemic and pulmonary circulations. This impression was confirmed by the measurement and comparison of the lumento-wall ratios of the small muscular pulmonary arteries in the two infants with patent ductus arteriosus, in 26 controls, and in 22 patients with congenital heart disease who survived the immediate postnatal period. Each of the 22 patients had an aorto-pulmonary or ventricular septal defect of sufficient size to equalize systolic pressures between the pulmonary and systemic circulations. We consider that this histological observation has a physiological basis of clinical importance which determines whether infants with patent ductus arteriosus survive or die in the neonatal period.

* Dr. Heath was in receipt of a Rockefeller Travelling Fellowship in Medicine while participating in this investigation, which was supported in part by a research grant, No. H3531, from the National Heart Institute, National Institutes of Health, United States Public Health Service.
Method AND MATERIAL

Portions from the upper or lower lobes of the lungs in each case studied were embedded in paraffin. Sections were stained by Verhoeff's method to demonstrate elastic tissue and counterstained with van Gieson's stain to show collagen and muscle. The thickness of the media of small muscular arteries, less than $100 \mu$ in external diameter, was measured after the method of Dammann and Ferencz (1956) with the modification that intimal tissue was not included in the measurements of the media. The diameter of the lumen of the vessel was measured and divided by twice the thickness of the media, thus giving an index which expresses a ratio of size of lumen to thickness of wall. These measurements were restricted to arteries of this diameter as the ratio tends to diminish in larger vessels; hence, ratios calculated from arteries of various sizes are not comparable. In each instance 10 to 20 vessels were measured and importance was attached to the necessity of systematic examination of the section. Selective examination and mensuration of arteries leads to an erroneous ratio which usually tends to be too low, as the observer has a natural tendency to select vessels with a thick, wellformed media. With these reservations, the lumen-towall ratio was found to be fairly constant for any particular case.

Only early cases of hypertensive pulmonary vascular disease without severe intimal fibrosis were included in the study, for, when occlusive changes of this type develop, the vessels undergo progressive dilatation with progressive thinning of the media. In most of the cases studied there was only an increase in the medial thickness of the muscular pulmonary arteries without intimal fibrosis, and in the few cases in which intimal fibrosis was present it was minimal. In the later fibrotic stage of pulmonary vascular disease there is no fixed relation between the thickness of the media of single vessels and the level of the total pulmonary vascular resistance, since 
grossly hypertrophied and thinned vessels exist together in one section of lung. Hence, the measurement of lumen-to-wall ratios in cases with severely fibrosed arteries is valueless as an expression of the state of the media.

Three groups of patients were studied. The first (Group 1) consisted of 26 controls (Table I) who ranged in age from two newborn premature babies, each of

TABLE I

LUMEN-TO-WALL RATIOS IN CONTROL GROUP OF 26 PATIENTS

\begin{tabular}{|c|c|c|c|c|}
\hline Age Range & & & $\begin{array}{c}\text { No. of Patients } \\
\text { Examined }\end{array}$ & $\begin{array}{l}\text { Lumen-to-wall } \\
\text { Ratio (Mean) }\end{array}$ \\
\hline $\begin{array}{l}\text { Prematurity } \\
\text { First day of life } \ldots \\
\text { Remainder of first month } \\
9 \text { months to } 1 \text { year. } \\
1 \text { to } 2 \text { years. . }\end{array}$ & $\begin{array}{l}\cdots \\
\cdots \\
\cdots \\
\cdots\end{array}$ & $\begin{array}{l}\ldots \\
\ldots \\
\ldots \\
\ldots \\
\ldots\end{array}$ & $\begin{array}{l}5 \\
4 \\
8 \\
5 \\
4\end{array}$ & $\begin{array}{l}1 \cdot 0: 1 \\
1 \cdot 4: 1 \\
2 \cdot 3: 1 \\
8 \cdot 4: 1 \\
8 \cdot 0: 1\end{array}$ \\
\hline
\end{tabular}

whose foetal age was $: \frac{1}{2}$ months, to an infant of 23 months. Cardiac catheterization had not been carried out in any of these, but none had diseases which predispose to pulmonary hypertension.

The second group (Group 2) consisted of 22 patients (Cases 1 to 22 inclusive) who had congenital heart disease characterized by ventricular septal defect without pulmonary stenosis or a large patent ductus arteriosus which allowed the left ventricular systolic pressure to be directly transmitted to the pulmonary circulation from birth (Table II). The age range in this group was
11 days to 13 years. In 13 instances cardiac catheteriza tion had been performed, at which time the pulmonary artery mean blood pressures had been measured, and data had been collected which allowed a calculation of the total pulmonary vascular resistance. With one exception (Case 10) the radial artery mean blood pressure and the systemic vascular resistance had been measured so that the ratio of the total pulmonary resistance to the systemic resistance was also known. In two additional cases only the mean blood pressures in the pulmonary artery and radial artery (Case 19) or in the radial artery alone (Case 22) were known.

The third group (Group 3) consisted of two infants (Cases 23 and 24) each of whom was born with a wide patent ductus arteriosus and died from pulmonary oedema on the second day of life (Table II). In neither infant was the blood pressure in the pulmonary artery measured. A large atrial septal defect was also present in Case 23. These two patients are considered as a separate group because, although the underlying haemodynamic abnormalities in them are similar to those in Group 2, the state of the pulmonary blood vessels was different, as will be seen in the next section.

\section{RESULTS}

The lumen-to-wall ratios of the control group are shown in Table I where they are subdivided into five age groups. The ratio was $1.0: 1$ in the premature babies but had risen to a mean value

TABLE II

LUMEN-TO-WALL RATIOS IN GROUP 2 (22 CASES) AND IN GROUP 3 (TWO CASES)

\begin{tabular}{|c|c|c|c|c|c|c|c|c|}
\hline \multirow{2}{*}{$\begin{array}{l}\text { Group and } \\
\text { Case No. }\end{array}$} & \multirow{2}{*}{ Age } & \multirow{2}{*}{ Sex } & \multirow{2}{*}{$\begin{array}{c}\text { Disease } \\
\text { or } \\
\text { Condition* }\end{array}$} & \multirow{2}{*}{$\begin{array}{c}\text { Mean } \\
\text { Lumen-to-wall } \\
\text { Ratio }\end{array}$} & \multirow{2}{*}{$\begin{array}{c}\text { Total Pulmonary } \\
\text { Vascular } \\
\text { Resistance } \\
\text { (dynes } \\
\text { sec. } / \mathrm{cm}^{-5} \text { ) }\end{array}$} & \multirow{2}{*}{$\begin{array}{l}\text { Ratio of Total } \\
\text { Pulmonary } \\
\text { Resistance } \\
\text { to Systemic } \\
\text { Resistance }\end{array}$} & \multicolumn{2}{|c|}{$\begin{array}{c}\text { Mean Blood } \\
\text { Pressure }(\mathrm{mm} . \mathrm{Hg})\end{array}$} \\
\hline & & & & & & & $\begin{array}{l}\text { Pulmonary } \\
\text { Artery }\end{array}$ & $\begin{array}{l}\text { Radial } \\
\text { Artery }\end{array}$ \\
\hline $\begin{array}{c}\text { Group } 2 \\
1 \\
2 \\
3 \\
4 \\
5 \\
6 \\
7 \\
8 \\
9 \\
10 \\
11 \\
12 \\
13 \\
14 \\
15 \\
16 \\
17 \\
18 \\
19 \\
20 \\
21 \\
22\end{array}$ & $\begin{array}{c}11 \text { days } \\
6 \text { weeks } \\
4 \frac{1}{2} \text { months } \\
67, ", \\
7 \\
7 \\
10 \quad, ", \\
1 \text { year ", } \\
1 \text {,', } \\
15 \text { months } \\
1 \frac{1}{2} \text { years } \\
22,, \\
2 \\
2 \frac{1}{2},, \\
5 \\
5 \\
6 \frac{1}{2}, ", \\
9 \\
10, ", \\
11 \\
13, ", \\
\end{array}$ & $\begin{array}{l}\mathbf{M} \\
\mathbf{M} \\
\mathbf{M} \\
\mathbf{M} \\
\mathbf{M} \\
\mathbf{F} \\
\mathbf{M} \\
\mathbf{F} \\
\mathbf{F} \\
\mathbf{M} \\
\mathbf{M} \\
\mathbf{M} \\
\mathbf{F} \\
\mathbf{M} \\
\mathbf{M} \\
\mathbf{F} \\
\mathbf{M} \\
\mathbf{M} \\
\mathbf{M} \\
\mathbf{F} \\
\mathbf{F} \\
\mathbf{M}\end{array}$ & $\begin{array}{l}\text { PDA } \\
\text { PDA } \\
\text { VSD } \\
\text { CTB } \\
\text { VSD } \\
\text { VSD } \\
\text { VSD; ASD } \\
\text { VSD; ASD } \\
\text { AVC } \\
\text { VSD } \\
\text { VSD } \\
\text { VSD; PDA } \\
\text { AVC } \\
\text { VSD } \\
\text { AVC } \\
\text { VSD; MI } \\
\text { PDA } \\
\text { VSD; PDA } \\
\text { CTB } \\
\text { PDA } \\
\text { VSD } \\
\text { VSD; T }\end{array}$ & $\begin{array}{l}1 \cdot 7: 1 \\
1 \cdot 7: 1 \\
1 \cdot 0: 1 \\
1 \cdot 3: 1 \\
1 \cdot 6: 1 \\
2 \cdot 4: 1 \\
1 \cdot 2: 1 \\
1 \cdot 8: 1 \\
2 \cdot 2: 1 \\
2 \cdot 2: 1 \\
2 \cdot 5: 1 \\
2 \cdot 8: 1 \\
2 \cdot 2: 1 \\
1 \cdot 9: 1 \\
2 \cdot 3: 1 \\
4 \cdot 8: 1 \\
1 \cdot 2: 1 \\
1 \cdot 2: 1 \\
2 \cdot 0: 1 \\
3 \cdot 8: 1 \\
2 \cdot 3: 1 \\
4 \cdot 0: 1\end{array}$ & $\begin{array}{l}1,720 \dagger \\
1,160 \\
1,500 \dagger \ddagger \\
5,100 \\
1,290 \\
1,550 \ddagger \\
\\
510 \\
850 \\
1,990 \\
1,170 \dagger \\
1,730 \\
2,300 \\
680\end{array}$ & $\begin{array}{l}0 \cdot 5: 1 \\
\\
0 \cdot 2: 1 \\
0 \cdot 4: 1 \\
\\
0 \cdot 7: 1 \\
1 \cdot 0: 1 \\
0 \cdot 2: 1 \\
0 \cdot 7: 1 \\
0 \cdot 9: 1 \\
0 \cdot 7: 1 \\
0 \cdot 9: 1 \\
1 \cdot 0: 1 \\
0 \cdot 6: 1\end{array}$ & $\begin{array}{l}49 \\
\\
48 \\
48 \\
54 \\
45 \\
66 \\
34 \\
66 \\
53 \\
57 \dagger \\
67 \\
80 \\
76 \\
69\end{array}$ & $\begin{array}{l}57 \\
63 \\
66 \\
67 \\
48 \\
63 \\
74 \\
80 \\
77 \\
77 \\
77\end{array}$ \\
\hline $\begin{array}{c}\text { Group } 3 \\
23 \\
24\end{array}$ & $\begin{array}{l}2 \text { days } \\
2,,\end{array}$ & $\begin{array}{l}\mathbf{M} \\
\mathbf{M}\end{array}$ & $\begin{array}{l}\text { PDA; ASD } \\
\text { PDA }\end{array}$ & $\begin{array}{l}3 \cdot 6: 1 \\
4 \cdot 5: 1\end{array}$ & & & & \\
\hline
\end{tabular}

- Abbreviations used: PDA = patent ductus arteriosus (wide); ASD=atrial septal defect ; VSD = ventricular septal defect (large); AVC= common atrioventricular canal; $\mathrm{T}=$ corrected transposition; $\mathrm{MI}=$ mitral incompetence; CTB $=$ cor triloculare biatriatum (without pulmonary stenosis).

+ Measurements while patient was breathing $100 \%$ oxygen.

The calculation of the pulmonary blood flow and hence of the total pulmonary resistance is open to some error due to uncertainty as to the oxygen saturation of pulmonary vein blood. 

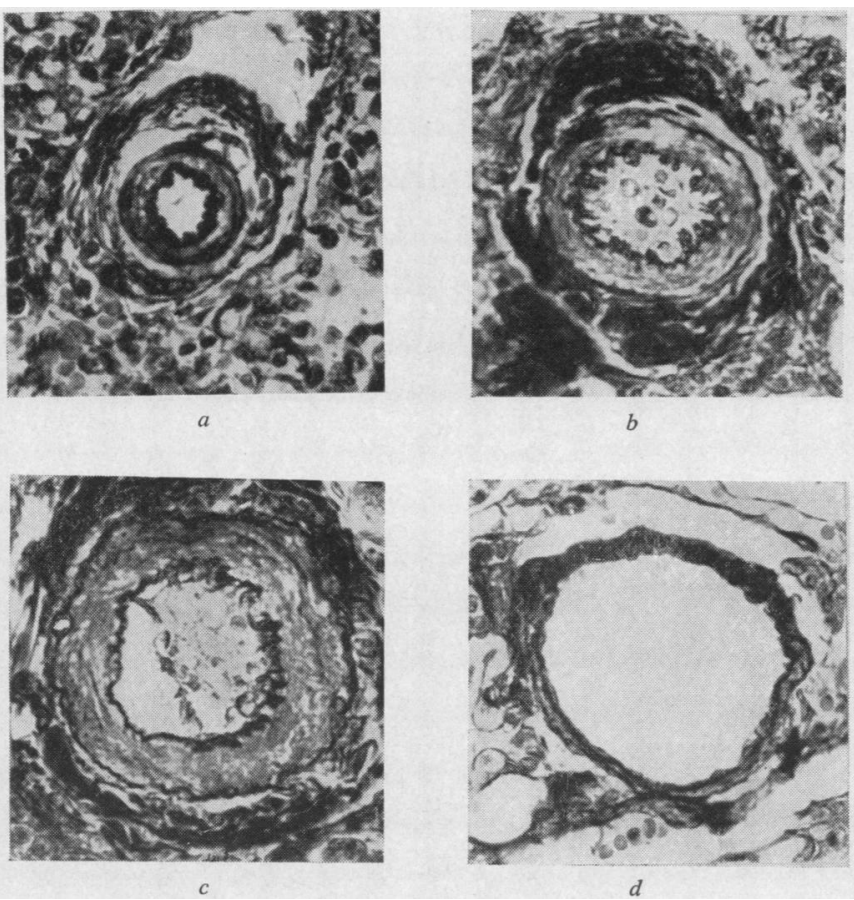

Fig. 1. $-a$, Transverse section of a small muscular pulmonary artery from a control 1-day-old infant. The lumen-to-wall ratio of this vessel is $1.5: 1$. The media is much thicker than in adult life. The mean lumen-to-wall ratio for all vessels of this case studied was 1.7: 1. This and all other photomicrographs are sections stained by Verhoeff's method for elastic tissue and counterstained with van Gieson's connective tissue stain (ELVG) $\times 375$. $b$, Transverse section of a small pulmonary artery from a male infant, aged $1 \frac{1}{2}$ years, with ventricular septal defect (Case 11). The lumen-to-wall ratio of this vessel is $2: 1$. The media is thus abnormally thick, the appearances being those found in the normal foetus or in the normal infant in the first few weeks of life. The mean lumen-:o-wall ratio for all vessels of this case studied was $2.5: 1$. The total pulmonary vascular resistance was 1,290 dynes/second $/ \mathrm{cm} .^{-5}$ (stain, ELVG; $\times 375$ ). $c$, Transverse section of a small pulmonary artery from a boy, aged 9 years, having cor triloculare biatriatum without pulmonary stenosis (Case 19). The lumen-to-wall ratio of this vessel is 1.4: 1. The media is abnormally thick; at this age the normal ratio is $8: 1$. The mean lumen-to-wall ratio for all vessels of this case studied was $2: 1$. The pulmonary artery mean blood pressure was $80 \mathrm{~mm}$. $\mathrm{Hg}$, suggesting that a high total pulmonary vascular resistance was present (stain, ELVG; $\times 375$ ). $d$, Transverse section of a small pulmonary artery from a 5-year-old girl with a ventricular septal defect (Case 16). The lumento-wall ratio of this vessel is $7: 1$, although the total pulmonary resistance was 1,990 dynes/second $/ \mathrm{cm}^{-5}$ In this case the artery, which showed intimal fibrosis, has been distended by the high pulmonary artery blood pressure so that its media is of normal thickness. A comparison of this figure with Fig. $1 b$ shows that there is no fixed relation between the medial thickness of single vessels and total pulmonary vascular resistance as discussed in the text. The mean lumen-to-wall ratio for all vessels of this case studied was 4.8: 1 (stain, ELVG; $\times$ 375).

of $2.3: 1$ by the first month of life (Fig. 1a). By the end of the first year of life the ratio was $8.4: 1$ and a similar value was found in the second year.

The lumen-to-wall ratios in the cases of congenital heart disease here studied are shown in Table II, together with the corresponding mean blood pressure in the pulmonary artery and total pulmonary vascular resistance when known. In the first month of life the ratio was 1.7:1, indicating abnormally thick medial coats. It remained at this abnormally thick level throughout the first three years of life. The highest ratio recorded in the first year of life was in a patient in whom the ratio was $2.4: 1$. Among patients between 1 and $3 \frac{1}{2}$ years of age the highest ratio was 2.8:1 (Fig. $1 b$ and $c$ ).

Four of the seven patients more than 5 years of age had abnormally thick small muscular pulmonary arteries, the lumento-wall ratio ranging from $1.2: 1$ (Cases 17 and 18) to 2.3:1 (Case 21). However, the remainder in this age group had a ratio which was greater, ranging from 3.8:1 in Case 20 to $4.8: 1$ in Case 16 (Fig. 1d), but which still was far below the ratio of $8.4: 1$ noted at the end of the first year of life in the control group.

The lumen-to-wall ratios of the two patients with patent ductus arteriosus who died from pulmonary oedema on the second day of life were higher, at 3.6: 1 and 4.5:1, than one would expect in a child of this age with congenital heart disease and a common ejectile force (Fig. $2 a, b, c$, and $d$ ). Moreover these ratios were even higher than one would expect in a normal child in the first month of life.

\section{COMMENT}

The thick muscular pulmonary arteries of the normal foetus (Table I and Fig. 1a) are an anatomical expression of the underlying haemodynamic conditions. Since the foetal pulmonary arterial bed is in free communication with the descending aorta through the patent ductus arteriosus, the blood pressure in the pulmonary arteries, the aorta, and the two ventricles is of the same magnitude. In order to allow most of the blood from the right ventricle to be propelled through the ductus and hence on to the aorta and placenta, there must be high resistance to flow in the lungs. This high resistance, which underlies the pulmonary hypertension, is probably mainly a result of constriction of the thick-walled small muscular pulmonary arteries in which the lumen-to-wall ratio has been shown to be as low as $1.0: 1$, although the collapsed nature of the lung also may play a part in causing a high resistance to flow (Edwards, 1957). As a 

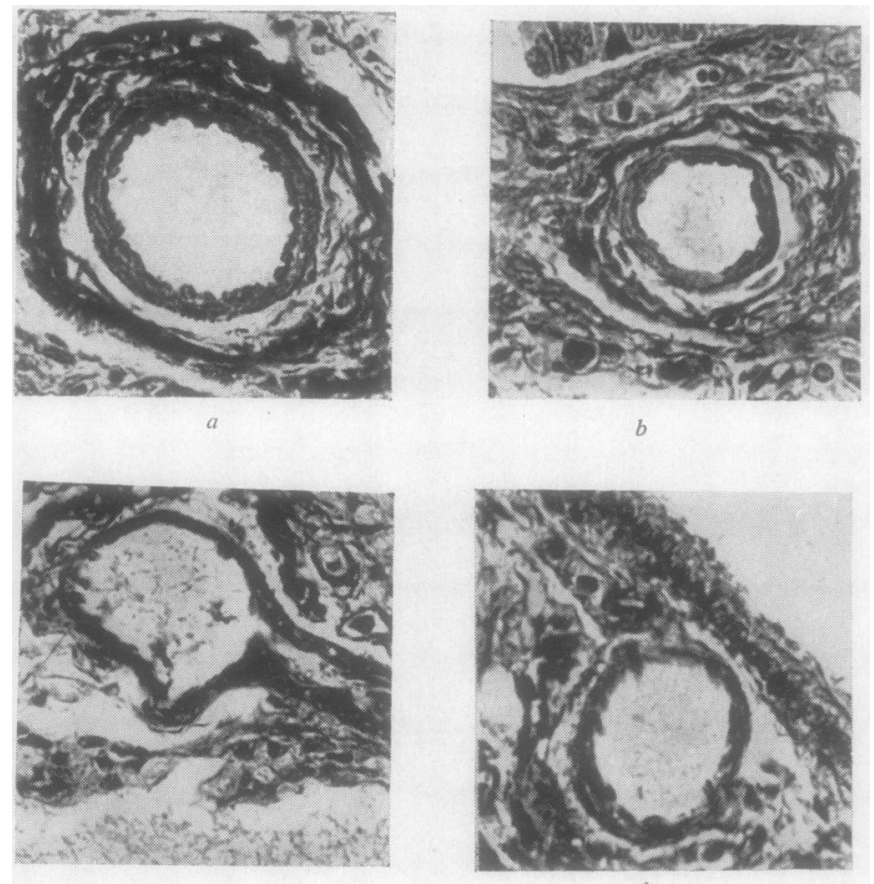

FIG. 2.-Transverse section of small pulmonary arteries in Cases 23 ( $a$ and $b$ ) and $24(c$ and $d)$. Both patients were male infants with wide patent ductus arteriosus who died from pulmonary oedema on the second day of life. $a$. The lumen-to-wall ratio of this vessel is $5.5: 1 . \quad b$, The lumen-to-wall ratio of this vessel is $4: 1$. The mean lumen-to-wall ratio for all vessels in Case 23 was 3.6: 1 (stain in both, ELVG $\times 375$ ). $c$, The lumen-to-wall ratio of this vessel is $5.3: 1(\times 375) . d$, The lumen-to-wall ratio of this vessel is 4.5: $1(\times 400)$. The mean lumen-to-wall ratio for all vessels in Case 24 was 4.5: 1 (stain in both, ELVG). In all cases the mean lumen-to-wall ratios indicate that the media is abnormally thin for this age.

rule, when the free communication between the systemic and pulmonary circulations is closed by obliteration of the ductus arteriosus, the resistance falls in the lesser circulation with a resultant drop in blood pressure even though there is a rise in pulmonary blood flow. These physiological changes are associated with the marked thinning of the media in the normal vessel that we have observed so that, by the end of the first year of life, the vessel of $100 \mu$ in diameter has a medial thickness equivalent to only $5 \%$ of the external diameter of the vessel. In other words, the lumen-to-wall ratio rises from 1.0:1 to 8.0: 1 in a year (Table I).

In the patient with congenital heart disease who has a large ventricular septal defect or a wide aorto-pulmonary defect, the free communication between the systemic and pulmonary circulations is not abolished at birth. The small pulmonary arteries remain thick-walled so that in many cases a lumen-to-wall ratio of less than 2.0:1 persists into adolescence or even adult life (Fig. $1 b$ and $c$ ). These thick-walled, small-lumened vessels maintain a high resistance to pulmonary flow, which ranges in our series from 510 to 5,100 dynes/second $/ \mathrm{cm}^{-5}$ and is associated with pulmonary hypertension as shown in Table II. According to BarrattBoyes and Wood (1958) the normal total pulmonary resistance in adults is 90 to 290 dynes $/$ second $/ \mathrm{cm}^{-5}$ The high pulmonary resistance often present in cases with a common ejectile force prevents an excessive pulmonary blood flow which would lead to cardiac failure and pulmonary oedema associated with a high pulmonary flow.

When the duration of the pulmonary hypertension is prolonged, the walls of the small pulmonary arteries may become distended by the excessive blood pressure and then the lumen-to-wall ratio increases, as seen in Cases 16, 20, and 22 (Table II and Fig. 1d). Hence, thinning of the media can occur in association either with a diminution or exaggeration of resistance in the pulmonary circulation.

With this background we may now discuss the finding of thin-walled small muscular pulmonary arteries in the two newborn patients with widely patent ductus arteriosus (Fig. $2 a, b, c$, and $d$ ). Even if a communication between the two systems did not exist, this finding would indicate an unduly rapid transition to the thin-walled adult type of pulmonary vessel. However, when this transition occurs in association with a widely patent ductus arteriosus as in the present cases, the haemodynamic situation is apparently incompatible with survival. The thin-walled arteries are unable to maintain a high vascular resistance to the left-to-right shunt and this quickly results in excess pulmonary blood flow leading to cardiac failure and fatal pulmonary oedema. Probably only a small proportion of infants who die in the first few days of life do so as a result of the complications of a patent ductus arteriosus which is common at this age. We consider, however, that this small proportion could be detected by an examination of the small muscular pulmonary arteries to ascertain the thickness of the medial coats.

\section{Summary AND Conclusions}

The lumen-to-wall ratios of muscular pulmonary arteries, less than $100 \mu$ in diameter, were measured in 26 infants less than 2 years of age who did not have congenital heart disease, in 22 patients having 
congenital ventricular or aorto-pulmonary defects of sufficient size to equalize systolic pressures between the systemic and pulmonary circulations, and in two infants with widely patent ductus arteriosus who died from pulmonary oedema on the second day of life. Data concerning the total pulmonary vascular resistance and mean blood pressure in the pulmonary artery were known in 13 cases. The ratio of the total pulmonary to the systemic resistance was known in 12 of these cases. In two additional cases only the mean blood pressures in the pulmonary artery and radial artery or in the radial artery alone were known.
The results suggest that, in the newborn patient in whom patent ductus arteriosus is the rule, unduly rapid transition from the foetal thickwalled pulmonary artery to the thin-walled adult type of vessel may result in fatal pulmonary oedema as a complication of left ventricular failure resulting from a large left-to-right shunt.

\section{REFERENCES}

Barratt-Boyes, B. G., and Wood, E. H. (1958). J. Lab. clin. Med., $51,72$.

Dammann, J. F., Jr., and Ferencz, C. (1956). Amer. Heart J., 52, 7. Edwards, J. E. (1957). Circulation, 15, 164. 